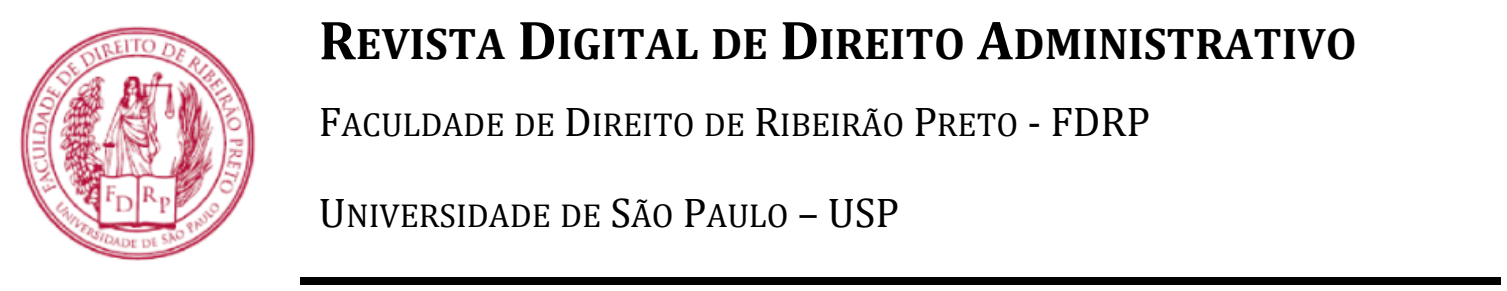

Seção: Artigos Científicos

\title{
O regime jurídico das empresas estatais no Brasil e seu papel na promoção do de- senvolvimento nacional
}

\author{
The legal regime of state-owned companies in Brazil and its role in promoting national develop- \\ ment
}

\section{Danilo Vieira Vilela, Bruna Cabrera de Bonito}

\begin{abstract}
Resumo: 0 presente artigo busca discutir o regime jurídico e o papel das empresas estatais no Brasil. Para tanto, parte-se de uma análise do modelo de intervenção do Estado brasileiro na ordem econômica para, a seguir, abordar os principais aspectos da disciplina jurídica das estatais, conforme a Lei no 13.303/2016. Posteriormente, busca-se compreender o perfil das estatais no Brasil hoje, tomando-se como ponto de partida a evolução histórica dessas entidades no cenário econômico-administrativo brasileiro. Metodologicamente, utiliza-se de uma pesquisa dedutiva para, ao final, demonstrar a relevância das empresas estatais como instrumentos da intervenção do Estado na economia, aptos a promover a retomada do desenvolvimento nacional.
\end{abstract}

Palavras-chave: empresas estatais; ordem econômica; empresa pública; sociedade de economia mista

\begin{abstract}
This paper seeks to discuss the legal regime and the role of state-owned companies in Brazil. To do so, it starts with an analysis of the Brazilian State's intervention model in the economic order to, next, address the main aspects of the legal discipline of the state companies, according to Law No. 13,303 / 2016. Subsequently, seek to understand the profile of state-owned companies in Brazil today, taking as a starting point the historical evolution of these entities in the Brazilian economic-administrative scenario. Methodologically, it uses a deductive research to, in the end, demonstrate the relevance of state-owned companies as instruments of State intervention in the economy, able to promote the resumption of national development.
\end{abstract}

Keywords: state-owned companies; economic order; public company; private and public joint stock company

Disponível no URL: www.revistas.usp.br/rdda

DOI: http://dx.doi.org/10.11606/issn.2319-0558.v7n2p269-291

Este conteúdo está protegido pela lei de direitos autorais. É permitida a reprodução, desde que indicada a fonte como "Conteúdo da Revista Digital de Direito Administrativo". A RDDA constitui periódico científico da FDRP/USP, cuja função é divulgar gratuitamente pesquisa na área de direito administrativo. Editor responsável: Professor Associado Thiago Marrara. 


\title{
O REGIME JURÍDICO DAS EMPRESAS ESTATAIS NO BRASIL E SEU PAPEL NA PROMOÇÃO DO DESENVOLVIMENTO NACIONAL
}

\author{
Danilo Vieira VILELA*; Bruna Cabrera de BONITO**
}

Sumário: 1 Introdução; 2 A intervenção do Estado na economia; 3 As empresas estatais no direito brasileiro; 3.1 Conceito; 3.2 Criação e extinção; 3.3 Atividade desempenhada; 3.4 Regime jurídico; 3.5 Personalidade jurídica; 3.6 Regime de pessoal; 3.7 Responsabilidade civil; 3.8 Patrimônio; 3.9 Função social; 3.10 Fiscalização; 3.11 Falência; 40 papel das empresas estatais no desenvolvimento nacional; 5 Conclusão; 6 Referências Bibliográficas.

\section{Introdução}

Exemplo máximo da intervenção direta do Estado na ordem econômica, as empresas públicas e sociedades de economia mista (empresas estatais) têm sua disciplina jurídica atualmente prevista na lei no 13.303/2016 (Estatuto das Estatais). Entretanto, não obstante o regramento infraconstitucional, tais entidades da Administração Pública Indireta são previstas na Constituição da República Federativa do Brasil de 1988 (CRFB/88) como importantes instrumentos tanto do Direito Administrativo quanto do Direito Econômico.

Assim, o papel das empresas estatais tem variado significativamente no decorrer da História brasileira, oscilando conforme as variações da relação entre Direito e Economia, conduzida pelos rumos incertos da política brasileira.

Entretanto, independentemente da direção para a qual aponta a política nacional ora mais intervencionista, ora mais liberal - é imperioso reconhecer a relevância das empresas estatais no processo de busca pelo desenvolvimento nacional.

0 presente artigo tem como objetivo central discorrer sobre o regime jurídico das empresas estatais no Brasil, reconhecendo-as como resultado direto da intervenção do Estado na ordem econômica. No mais, pretende apontar o papel desempenhado pelas estatais no curso da história recente do país para, ao final, traçar um breve perfil das empresas estatais na realidade brasileira no final da segunda década do século XXI.

\footnotetext{
* Professor na Universidade do Estado de Minas Gerais (UEMG). Doutor em Direito Político e Econômico na Universidade Presbiteriana Mackenzie. Mestre em Direito Obrigacional Público e Privado pela Universidade Estadual Paulista (UNESP). Especialista em Direito Processual (UEMG), Especialista em Direito Penal e Processual Penal (UCDB), Especialista em Direito Empresarial e Advocacia Empresarial (Anhanguera-Uniderp) e MBA em Gestão Empresarial (UNESC). Membro do Grupo Caraíve de Relações Internacionais e Políticas Públicas e do Centro Brasileiro de Litígios Econômicos (CBLE). Professor de graduação e pós-graduação e em cursos preparatórios para concursos. Advogado e árbitro.
}

${ }^{* *}$ Bacharel em direito pela Universidade do Estado de Minas Gerais (UEMG). Ex-bolsista da FAPEMIG. 
Busca-se, dessa forma, enfatizar o papel das empresas estatais, evidenciando que uma boa disciplina jurídica, aliada à adequada observância dos ditames constitucionais no que diz respeito à ordem econômica, são, inexoravelmente, necessárias à retomada do desenvolvimento econômico e social brasileiros.

Como método de abordagem, utilizou-se do método dedutivo, partindo-se da ideia de que as estatais historicamente foram e são responsáveis pela industrialização nacional, atuando em diferentes setores públicos, aptas, portanto, a promover, em todas as suas modalidades, o desenvolvimento nacional. Por sua vez, o método de procedimento utilizado foi o histórico, através do estudo do surgimento e processos históricos das empresas estatais, a fim de verificar sua influência na sociedade atual.

\section{A intervenção do Estado na economia}

A ascensão do pensamento econômico no contexto internacional, segundo Figueiredo (2014, p. 63), possui como ponto nevrálgico o enfraquecimento do Estado Absolutista. Esse modelo absolutista, que concentrava todos os poderes em torno do monarca, baseava-se no direito supremo do rei sobre o Estado.

Em resposta às arbitrariedades consumadas pelo rei no período absolutista, surge na sociedade a preocupação em assegurar seus direitos e garantias individuais (FIGUEIREDO, 2014, p. 63). 0 grande expoente desse momento histórico foi a Revolução Francesa (1789), da qual resultou a Declaração Universal dos Direitos do Homem e do Cidadão, documento que defende ideais de liberdade, igualdade e fraternidade.

Baseado nessa consciência do direito de liberdade individual, somado ao mercantilismo que fomentou trocas comerciais e o avanço da burguesia com o surgimento do capital, o Estado Absoluto perdeu espaço, emergindo o Estado Liberal (FIGUEIREDO, 2014, p. 64). Este último deliberava seus esforços em apenas dois sentidos: assegurar a segurança pública (interno) e preservar a ordem (externo). No tocante aos demais cenários (inclusive jurídico), competia ao livre-arbítrio das partes interessadas, que efetivavam seus direitos e liberdades individuais de maneira indiscriminada (ou seja, ausente de um mecanismo limitador) (FIGUEIREDO, 2014, p. 64).

Todavia, tal sistema presumia "um ambiente concorrencialmente perfeito, para que, através da competição equilibrada entre os agentes, se alcançasse os interesses coletivos" (FIGUEIREDO, 2014, p. 64). No entanto, essa suposição se sustentou apenas no campo ideológico, porquanto os fatores de produção (recursos naturais, trabalho e capital) e riquezas se aglutinaram na posse de minorias (MALUF, 2018, p. 125).

Visto que o ideal liberal não se efetivou como pretendido, principalmente em razão do aumento das desigualdades sociais (internos) e declínios econômicos interna- 
cionais (externos), além de combates bélicos mundiais, definiu-se assim a queda de tal modelo (FIGUEIREDO, 2014, p. 64).

Em decorrência dos supracitados incidentes internos e mundiais, emergiu um novo paradigma estatal: o Estado Intervencionista, substituindo a prevalência da autonomia individual pelo dirigismo estatal na ordem econômica.

Entretanto, essa absorção estatal do setor econômico gerou um aumento da máquina pública, acarretando gastos maiores do que a receita (ou seja, um déficit no orçamento público). Tomado pelo endividamento e ineficiência com as demandas sociais, a atuação estatal desencadeou descrédito pela população no seu "potencial empresário e provedor" (FIGUEIREDO, 2014, p. 65).

Em razão disso, o enfraquecimento do Estado Interventor deu espaço à volta de alguns comedidos ideais liberais (essencialmente na economia), que se consagrou com a ascensão do Estado Regulador. Sua função era atuar apenas na condição de regulamentador da Ordem Econômica, apresentando um novo papel para o Estado.

Esse papel (disciplinador) desenvolvido pelo Estado, no caso do Brasil, é resultado do princípio constitucional da livre-iniciativa (art. 170, CRFB/88). Ele estabelece como regra à iniciativa privada o exercício da atividade econômica (fundamento do regime capitalista), cabendo ao Estado regular a ordem econômica.

Tal atividade regulatória (ou atuação indireta) objetiva "estabelecer as regras disciplinadoras da ordem econômica" (CARVALHO FILHO, 2017, p. 975), de modo a ratificar o comportamento a ser seguido pelo mercado (iniciativa privada). Todavia, essa atuação indireta não se confunde com a atuação empresária do Estado (ou intervenção $\operatorname{direta}^{1}$ ).

O conceito de Estado Empresário (ou execução direta da atividade econômica) é fundado no princípio da subsidiariedade, devendo, portanto, ser exercido de modo restritivo. Tal parâmetro permite a atuação estatal apenas quando houver omissão ou ausência da iniciativa privada na satisfação dos interesses coletivos (OLIVEIRA, 2017, p. 567).

Nessa diretriz, segundo o Ministro Eros Grau em decisão no Supremo Tribunal Federal:

\footnotetext{
${ }^{1}$ Ao contrário da corrente doutrinária majoritária, Carvalho Filho (2017, p. 989-992), de forma isolada, defende que a exploração direta do Estado se dá através de seus órgãos internos (como por exemplo, uma Secretaria Municipal que fornece medicamentos à população de baixa renda), visto que o Poder Público atua sem intermédios para persecução da atividade econômica, efetiva de maneira direta. Já por intervenção indireta, o autor argumenta que se concretiza por meio da criação de pessoas jurídicas vinculadas ao Estado, as chamadas empresas estatais (que podem ser empresas públicas ou sociedades de economia mista), com o intuito de desempenhar atividades comerciais. Em razão dessa criação de entidades controladas e dirigidas pelo Poder Público para executar tal fim, o Estado explora indiretamente atividade econômica, utilizando-se de um intermediário.
} 
É certo que a ordem econômica na Constituição de 1988 define opção por um sistema, o sistema capitalista, no qual joga um papel primordial a livre-iniciativa. Essa circunstância não legitima, no entanto, a assertiva de que o Estado só intervirá na economia em situações excepcionais. Muito pelo contrário. [...] Mais do que simples instrumento de governo, a nossa Constituição enuncia diretrizes, programas e fins a serem realizados pelo Estado e pela sociedade. [...] A livre-iniciativa é expressão de liberdade titulada não apenas pela empresa, mas também pelo trabalho. Por isso a Constituição, ao contemplá-la, cogita também da "iniciativa do Estado"; não a privilegia, portanto, como bem pertinente apenas à empresa. Se de um lado a Constituição assegura a livre-iniciativa, de outro determina ao Estado a adoção de todas as providências tendentes a garantir o efetivo exercício do direito à educação, à cultura e ao desporto [arts. 23, inciso V, 205, 208, 215 e 217, § 3ํㅡ, da Constituição]. Na composição entre esses princípios e regras há de ser preservado o interesse da coletividade, interesse público primário. (BRASIL, 2005, p. 5963).

Assim, essa atividade estatal direta, quando exercida, sujeita-se a dois requisitos elencados pela Constituição da República (1988) no seu art. 173: imperativos da segurança nacional ou a relevante interesse coletivo, cujo alcance cabe à lei ordinária, na medida em que se tratam de conceitos jurídicos indeterminados e sujeitos à discricionariedade do gestor público (DI PIETRO, 2017, p. 602).

Nesse sentido, a lei no 13.303/16 (Estatuto das Estatais), ao tratar sobre o relevante interesse coletivo, disciplina que a execução deste "[...] deverá ser orientada para o alcance do bem-estar econômico e para a alocação socialmente eficiente dos recursos [...]" (art. 27, § 1ํo), além de ampliar o acesso dos consumidores aos produtos e serviços das estatais e desenvolver ou empregar a tecnologia nacional para produção e oferta de tais produtos e serviços (incisos I e II).

Apesar de não ser expressamente tratado na lei acima, o requisito de imperativo de segurança nacional também se inclui nessa finalidade mencionada. Segundo Carvalho Filho (2017, p. 991), trata-se ainda de um atributo notoriamente político, sendo necessário para garantia da soberania (própria existência e independência) do Estado, como atividades estratégicas de energia atômica, indústria bélica, telecomunicações e petróleo.

Presentes os pressupostos constitucionais (segurança nacional ou interesse coletivo), cabe à Administração Direta (União, Estados, Distrito Federal ou Municípios) a criação de meios para efetivação da interferência na Ordem Econômica. Conforme a CRFB/1988, em seu artigo 173, parágrafo primeiro, esses mecanismos são as empresas estatais, objeto de estudo deste trabalho. 


\section{As empresas estatais no direito brasileiro}

\subsection{Conceito}

O conceito de empresas estatais, segundo Di Pietro (2020, p. 546), abrange "todas as entidades, civis ou comerciais, de que o Estado tenha o controle acionário, diretamente ou por meio de outra entidade da administração indireta". Tal definição abrange a forma de empresas públicas, sociedades de economia mista, suas subsidiárias e demais empresas controladas pelo Estado.

Inicialmente, a Lei das Estatais (lei no 13.303/16) estabelece que a empresa pública "é [um]a entidade dotada de personalidade jurídica de direito privado, com criação autorizada por lei e com patrimônio próprio" (art. $3^{\circ}$ ). Ainda, no que tange ao capital social, é constituído de recursos provenientes exclusivamente do setor público, ou seja, "integralmente detido pela União, pelos Estados, pelo Distrito Federal ou pelos Municípios" (art. 3ํㅡㄹ lei no 13.303/16).

Todavia, entidades de direito público interno ou da Administração Indireta podem também integrar o capital social desde que a maioria do capital votante pertença ao ente instituidor, seja a União, Estados ou Municípios (art. 3o, parágrafo único, lei no 13.303/16). Neste sentido, esclarece Irene Nohara:

Desde que a maioria do capital votante permaneça em propriedade da União, do Estado, do Distrito Federal ou do Município, será admitida, no capital da empresa pública, a participação de outras pessoas jurídicas de direito público interno, bem como de entidades da Administração Indireta da União, dos Estados, do Distrito Federal e dos Municípios (NOHARA, 2019, p. 685).

Quanto à forma societária, apesar da empresa pública poder revestir-se de qualquer dos tipos admitidos em direito (sociedade civil, comercial, Ltda., anônima, unipessoal), há uma recomendação do Decreto Federal no 8.945/2016 (art. 11) para adoção da figura de sociedade anônima, sendo obrigatório para suas subsidiárias.

Em relação ao foro processual há uma diferença no tocante às empresas públicas federais e as demais empresas públicas (estaduais, distritais ou municipais). Enquanto as primeiras têm seus litígios tramitando na justiça federal (art. 109, I da CRFB), as últimas se submetem à justiça estadual.

São alguns exemplos de empresas públicas: Empresa Brasileira de Correios e Telégrafos, Caixa Econômica Federal, Banco Nacional de Desenvolvimento Econômico e Social e Empresa Brasileira de Serviços Hospitalares.

Já a sociedade de economia mista, apesar de contar com a participação do setor privado em seu capital social (NOHARA, 2019, p. 688), tem a maioria das ações com 
direito a voto pertencentes à União aos Estados, ao Distrito Federal, aos Municípios ou a entidade da Administração Indireta.

Quanto à forma de organização, a sociedade de economia mista atua somente sob a forma de sociedade anônima, regendo-se (além do Estatuto próprio das Estatais) pela Lei das Sociedades por Ações (lei no 6.404/1976). Dessa maneira, o capital privado é incorporado por meio de ações, adequando-se ao regime societário estabelecido (NOHARA, 2019, p. 688).

Por último, há que se destacar a competência da Justiça Comum para julgar as causas em que é parte sociedade de economia mista (Súmula 556, do STF). Apesar dessa regra, também há súmula no sentido de que o foro da sociedade de economia mista será a Justiça Federal, nos casos em que a União intervém como assistente ou opoente (Súmula 517, do STF).

São exemplos de sociedade de economia mista: Petrobrás, Eletrobrás, Banco do Brasil, Banco do Nordeste e Sabesp.

Insta salientar a importância das subsidiárias e demais empresas controladas pelo Estado, não se devendo confundi-las com as sociedades de mera participação do Estado, casos em que o Poder Público atua na condição de investidor.

As subsidiárias são conhecidas por empresas de segundo grau, uma vez que são entidades que não sofrem controle direto do ente federativo vinculado (União, Estado, Distrito Federal ou Município), mas sim indireto, por meio das empresas estatais (ou empresas de primeiro grau) (CARVALHO FILHO, 2020, p. 536). Estas possuem a função de auxiliar no desempenho das funções das últimas, diversificando a atuação no setor em que a empresa de primeiro grau opera.

Tome-se como exemplo a Petrobras. Ela atua na função de exploração e refino do petróleo. Todavia, no setor produtivo em que atua precisa armazenar e transportar o combustível até o consumidor, sendo necessária a presença da Transpetro (uma de suas subsidiárias) para tal atividade.

\subsection{Criação e extinção}

A constituição das empresas estatais se dá através de uma autorização legal (lei específica que envolva somente esse assunto), de iniciativa do chefe do Executivo, apontando de forma clara a razão de sua criação (art. $2^{\circ}$, $\S 2^{\circ}$, lei $n^{\circ}$ 13.303/16). Além disso, o seu nascimento depende de posterior registro do estatuto em órgão próprio.

No que tange à sua extinção, em razão de lacuna legislativa a respeito do assunto, a doutrina entende que também dependerá de autorização legal específica, de atitude do Poder Executivo. Tal fenômeno baseia-se no princípio da simetria ou paralelismo das formas (NOHARA, 2019, p. 682). 
Em relação às empresas estatais subsidiárias, o artigo $2^{\circ}$, $\S 2^{\circ}$ do Estatuto das Estatais aponta que a criação de tais entes também deve ocorrer por meio de uma autorização do Poder Legislativo.

Tal argumentação segue no sentido de que a reserva de lei em sentido formal prevista na Constituição (art. 173, caput) para autorizar a criação é justificada pela necessidade de que o Poder Legislativo delibere sobre o atendimento dos requisitos que autorizam a intervenção do Estado na economia (FONTOURA, 2019, p. 127).

Todavia, por meio da Ação Direta de Inconstitucionalidade no 5.624, em junho de 2019, o Supremo Tribunal Federal, por maioria, justificando-se tratar de interpretação conforme a Constituição, entendeu que "a exigência de autorização legislativa [...] não se aplica à alienação do controle de suas subsidiárias e controladas" (BRASIL, 2019, p. 2).

Deve-se levar em conta, todavia, que o texto constitucional, em seu artigo 37, XX, dispõe que "depende de autorização legislativa [...] a criação de subsidiárias das entidades mencionadas no inciso anterior, assim como a participação de qualquer delas em empresa privada". Assim, através do princípio da simetria, prevalecia o entendimento no sentido de que sua extinção ou alienação deveria ocorrer do mesmo modo.

Entretanto, segundo o entendimento recente da Suprema Corte, a venda das subsidiárias não exige autorização legislativa e nem licitação, devendo observar somente os princípios da Administração Pública. Assim:

[...] i) a alienação do controle acionário de empresas públicas e sociedades de economia mista exige autorização legislativa e licitação; e ii) a exigência de autorização legislativa, todavia, não se aplica à alienação do controle de suas subsidiárias e controladas. Nesse caso, a operação pode ser realizada sem a necessidade de licitação, desde que siga procedimentos que observem os princípios da administração pública inscritos no art. 37 da CF, respeitada, sempre, a exigência de necessária competitividade [...]. ADI 5624 MC-Ref/DF, rel. Min. Ricardo Lewandowski, julgamento em 5 e 6.6.2019. (BRASIL, 2019).

\subsection{Atividade desempenhada}

Conforme dispõe a Constituição da República, de 1988, as empresas estatais podem atuar na exploração de "atividade econômica de produção ou comercialização de bens ou de prestação de serviços" (art. 173, §1ํㅜ).

Assim, Carvalho Filho (2020, p. 538) aponta que o objeto geral de tais entidades administrativas é o exercício de atividade econômica em sentido lato (como gênero). Desse modo, as hipóteses estabelecidas na Constituição seriam duas: as atividades 
econômicas stricto sensu e os serviços públicos econômicos ${ }^{2}$. Conforme regramento constitucional, a atividade econômica em sentido estrito é exercida, em regra, por particulares e apenas excepcionalmente por empresas estatais que, regidas pelo artigo 173 da Constituição, podem atuar em regime de concorrência com a iniciativa privada ou como monopólio (OLIVEIRA, 2017, p. 119; NOHARA, 2019, p. 676).

Já em relação às prestadoras de serviço público (econômico), a principal diferença é a submissão ao artigo 175 da CRFB (e não ao art. 173), voltando sua atividade à prestação do serviço público. Assim, a lei criadora da estatal remete a titularidade do serviço à estatal, analogicamente ao que ocorre nas concessões ou permissões, devendo ser atribuição constitucional do ente criador (NOHARA, 2019, p. 678; DI PIETRO, 2020, p. 548).

Apesar da duplicidade do objeto desempenhado pelas estatais (atividade econômica e serviço público), ambas recebem o mesmo tratamento quanto às regras disciplinadoras, segundo o Estatuto das Estatais. Esse estatuto (a contrário da orientação constitucional) criou um regime jurídico homogêneo, não divergindo de acordo com a área de atuação da empresa (NOHARA, 2019, p. 677).

\subsection{Regime jurídico}

0 regime jurídico das empresas estatais foi disciplinado em 2016 pela Lei $\mathrm{n}^{\mathbf{0}}$ 13.303/16 (Estatuto das Estatais), que continha previsão constitucional no artigo 173, § 1ํ da CRFB desde 1988.

O estudo do regime jurídico das empresas estatais deve considerar que há parcialmente sujeição a normas de direito público (pois integram a Administração Pública Indireta) e parcialmente a normas de direito privado (pois são pessoas de direito privado) (CARVALHO FILHO, 2020, p. 539).

Contudo, em razão da Constituição submeter tais entidades ao regime jurídico das empresas privadas (art. $173, \S 1^{\circ}$, II), as derrogações de direito público serão apenas as elencadas de forma deliberada pelo próprio texto legal, ou seja, na ausência de normas constitucionais, sujeitam-se ao direito privado (DI PIETRO, 2020, p. 563).

Nesse sentido, Di Pietro dispõe que:

Essa sujeição parcial a normas de direito público justifica-se pelo fato de as empresas públicas e sociedades de economia mista (bem como suas subsidiárias) manterem vínculo com o ente político que as criou, para fins de controle, além do fato de administrarem total ou parcialmente recursos públicos e terem por objetivo a execução

\footnotetext{
${ }^{2}$ Estariam excluídos, portanto, do fim institucional os serviços públicos sem finalidade econômica, por apresentarem finalidade incompatível com a natureza das estatais (CARVALHO FILHO, 2020, p. 538).
} 
de atividades econômicas [em sentido lato] que o Estado presta por motivo de interesse público relevante ou por motivo de segurança nacional (DI PIETRO, 2020, p. 564).

Em outras palavras, é "essencial para manter a vinculação entre a entidade descentralizada e o ente que a instituiu; sem isso, deixaria ela de atuar como instrumento de ação do Estado" (DI PIETRO, 2020, p. 559).

No que tange às normas de direito público relacionadas na Constituição de 1988, são alguns exemplos: a sujeição ao controle do Tribunal de Contas (art. 71, II e III); a proibição de deputados e senadores, a partir da expedição do diploma, de firmarem ou manterem contrato (art. 54, I, a); a sujeição aos limites globais e condições para as operações de crédito externo e interno, fixados pelo Senado (art. 52, VII); a sujeição ao controle do Congresso Nacional (art. 49, X); a submissão aos princípios da Administração Pública (art. 37, caput); a aplicação aos empregados das normas sobre servidores constantes nos incisos do artigo 37; o estabelecimento das normas sobre licitações e contratos administrativos (art. 22, XXVII, combinado com art. 173, § 1ํo, III); a inclusão do orçamento fiscal, de investimento e da seguridade, na lei orçamentária anual (art. 165, § 5ํ); a exigência prévia de dotação orçamentária para a concessão de vantagem ou aumento de remuneração, criação de empregos ou alteração de estrutura de carreiras, bem como a admissão ou contratação de pessoal (art. 169, § 1ํㅡ, I) (DI PIETRO, 2020, p. 563-564).

Por outro lado, em razão de sua natureza jurídica, e da necessidade de se garantir a isonomia perante as demais empresas do setor, as empresas estatais também se submetem à normas de direito privado. Tal posicionamento foi desenvolvido pautado na facilidade e rapidez encontrada nas normas privadas para desempenhar a atividade econômica em sentido lato, fim para o qual foi criada.

\subsection{Personalidade jurídica}

Essa disposição para normas de direito privado deriva da personalidade jurídica desempenhada pelas estatais, qualificando-as como pessoas jurídicas de direito privado (natureza empresarial) (NOHARA, 2019, p. 678).

Em razão das normas de direito público apresentarem entraves e mecanismos de controle na sua atuação, o caráter de personalidade privada possibilita maior maleabilidade quando no desempenho de seu papel econômico (principalmente quando atuam no setor econômico) (CARVALHO FILHO, 2020, p. 534).

Tais normas exemplificam-se, por exemplo, na necessidade de registro em órgão específico no setor de atuação (art. 45 do CC), patrimônio próprio constituído por bens privados (art. 98 do CC), não gozar de privilégios fiscais (art. 173, $\S 2^{\circ}$ da CRFB), submissão dos funcionários ao regime celetista (art. 173, § 1ํㅡㄴ II da CRFB).

\subsection{Regime de pessoal}


0 regime celetista, regido pela Consolidação das Leis do Trabalho (CLT) aplicado a ambas as espécies de estatais é próprio das pessoas jurídicas de direito privado, por força do dispositivo constitucional "sujeição ao regime jurídico próprio das empresas privadas, inclusive quanto aos direitos e obrigações [...] trabalhistas [...]" (art. 173, § $1^{\circ}$, II da CRFB).

Todavia, em razão desses empregados atuarem como agentes públicos, submetemse a algumas normas constitucionais, tais como o ingresso através de concurso público (art. 37, II); a vedação à acumulação de cargos públicos (art. 37, XVII); a submissão ao teto remuneratório (art. 37, § 9ㅇ); a submissão à Lei de Improbidade Administrativa, sendo, ainda, considerados agentes públicos para fins penais (OLIVEIRA, 2017, p. 131).

\subsection{Responsabilidade civil}

Acerca da responsabilidade concernente às estatais, decorre da atividade desempenhada por ela. Nesse sentido, dispõe o artigo 37, § 60 da CRFB que "As pessoas jurídicas de [...] direito privado prestadoras de serviços públicos responderão pelos danos que seus agentes, nessa qualidade, causarem a terceiros".

Dessa forma, em relação às prestadoras de serviços públicos, a responsabilidade é objetiva pelos danos causados, ou seja, demonstrando-se o nexo causal entre a ação/omissão de tais entes e o prejuízo causado, já enseja o direito à indenização para a vítima.

Por outro lado, as entidades atuantes no domínio econômico, em regra, respondem subjetivamente (baseado na culpa), por receberem o mesmo tratamento das empresas privadas em geral (art. 173, § 1ํㅡ. II). Excepcionalmente, poderão responder de maneira objetiva, em virtude de regramentos específicos, como nos casos em que atuam como fornecedoras nas relações de consumo (OLIVEIRA, 2017, p. 134).

Essa responsabilidade será subordinada, de maneira secundária, ao ente federado (União, Estados, Distrito Federal ou Municípios) ao qual a estatal encontra-se subordinada, na circunstância de ausência de patrimônio para suprimir tal obrigação (OLIVEIRA, 2017, p. 134).

\subsection{Patrimônio}

Quanto ao patrimônio das estatais, por tratar-se de pessoa jurídica de direito privado, caracterizam-se por bens privados, uma vez que o Código Civil caracteriza como bens públicos somente os pertencentes a pessoas jurídicas de direito público interno (art. 98 do CC). Todavia, ao regime jurídico dos bens (predominantemente privado) incidem algumas características públicas, sobretudo na alienação e nos casos de estatais prestadoras de serviços públicos (OLIVEIRA, 2017, p. 131-132). 
Com relação às estatais que prestam serviço público, Irene Nohara (2019, p. 679) entende que seus bens se classificam como bens públicos de uso especial, pois destinam-se à realização de importantes funções , afastando-se, desse modo, a possibilidade de onerações das quais poderiam resultar a interrupção daquele serviço. Nesse sentido também o STF estendeu à Empresa Brasileira de Correios e Telégrafos (ECT) o "privilégio equivalente ao da Fazenda Pública [...] da impenhorabilidade dos bens, rendas e serviços" (BRASIL, 2002, p.431).

\subsection{Função social}

Outro ponto importante é relativo à função social das estatais, contida no artigo 173, § 1ํ, I da CRFB/88. Di Pietro (2020, p. 567) define como "o dever de exercer as suas atividades em benefício do bem comum”, pois o propósito da atuação do Estado no cenário econômico é a consecução do interesse coletivo.

Dessa forma, é mister a tais entidades terem como norte a efetuação do bem social, uma vez que a finalidade da sua criação é essa. Portanto, o direcionamento das ações estatais deve buscar o bem-estar econômico e o emprego eficiente dos recursos, possibilitando o desenvolvimento de tecnologia brasileira e práticas de sustentabilidade ambiental, além de responsabilidade social corporativa (art. 27 do Estatuto das Estatais).

Nesse sentido, cabe ressaltar que a produtividade ou lucro social gerado pela estatal no país deve ser privilegiado em detrimento do lucro econômico que tal ente possa gerar, uma vez que a estatal não precisa (e em alguns casos não deve) ter ganho econômico, podendo inclusive dar prejuízo (OCTAVIANI; NOHARA, 2019, p. 231). Portanto, a função da estatal é efetivar o interesse coletivo presente no texto constitucional.

\subsection{Fiscalização}

Além da função social, o artigo 173, § 1ํㅡ. I da CRFB prevê também às estatais "formas de fiscalização pelo Estado e pela sociedade". Segundo Carvalho Filho (2020, p. 556), estão submetidas a dois tipos de controle: interno e externo.

O primeiro demanda controle pelos próprios órgãos internos da entidade (auditoria interna, comitê estatutário, controle financeiro de publicidade), enquanto o segundo respeita práticas e métodos designados por entes públicos (Administração instituidora e sociedade).

O controle externo é empreendido diretamente pelo ente administrativo (União, Estado, Distrito Federal ou Município) cuja empresa estatal apresenta relação de vinculação. Além disso, a sociedade pode diretamente por meio de impugnação de editais, denunciar aos órgãos internos e Tribunal de Contas (CARVALHO FILHO, 2020, p. 556). 
Em relação ao controle pelo Tribunal de Contas, o artigo 87 do Estatuto estabeleceu que o controle independe da atividade desempenhada pela estatal, submetendo-as ao tribunal de contas respectivo. Contudo, esse controle não deve afetar a gestão e competências da empresa estatal.

O controle interno é previsto no Estatuto através de alguns instrumentos, somados à transparência que deve nortear a entidade. 0 primeiro mecanismo é a auditoria interna (feita pelo Conselho de Administração) que analisa a qualidade de gestão de riscos, processos de governança corporativa e controla finanças, além da criação de um Código de Conduta e Integridade (art. 9o do Estatuto) (CARVALHO FILHO, 2020, p. 557).

Ademais, o segundo é a elaboração de um comitê estatutário, a fim de acompanhar as indicações e avaliações dos integrantes do Conselho de Administração e o Fiscal (art. 10 do Estatuto). Por fim, o controle financeiro de publicidade, que visa impor limites devido ao desvio de recursos para contratações publicitárias (CARVALHO FILHO, 2020, p. 557).

Outra maneira de fiscalização das estatais é uma inovação prevista pela Lei das Estatais, o sistema de governança corporativa. Esse sistema reforça a transparência e o controle das estatais, a fim de "minimizar as possíveis falhas de integridade na conduta da alta gestão dessas empresas" (NOHARA, 2019, p. 690).

As normas sobre esse sistema encontram-se no Código Brasileiro de Melhores Práticas, que dispõe, segundo Nohara sobre:

Prestação de contas (accountability), a transparência ou disclosure, para que os stakeholders saibam da situação efetiva da empresa e tenham meios de mensurar os riscos dos investimentos que serão feitos, a equity ou equidade na composição de eventuais interesses divergentes entre acionistas, membros do Conselho de Administração e dirigentes das empresas e a compliance, que se realiza a partir da edição e da prática dos códigos de ética e de integridade organizacional (NOHARA, 2019, p. 690).

Trata-se, portanto, de um "microssistema que norteia as ações e diretrizes da entidade" (CARVALHO FILHO, 2020, p. 554), através de recomendações objetivas auxiliando na gestão da empresa.

\subsection{Falência}

A impossibilidade de falência nas empresas estatais foi tratada de maneira expressa na lei $\mathrm{n}^{\circ}$ 11.101/2005 (art. 2º , I), considerando, sobretudo, a responsabilidade subsidiária do ente ao qual a estatal encontra-se vinculada. 
Insta salientar que, segundo Di Pietro (2017, p. 641), o artigo $173, \S 1^{\circ}$, II da CRFB submete as estatais econômicas ao regime das empresas privadas (incluindo o regime falimentar), não atribuindo tratamento privilegiado às primeiras. Baseado nesse dispositivo, somente as prestadoras de serviço público deveriam estar excluídas de realizar o regime de falência (DI PIETRO, 2020, p. 584).

No entanto, levando em consideração a finalidade precípua da empresa estatal (relevante interesse coletivo ou segurança nacional), não cabe ao Judiciário privilegiar o interesse particular em detrimento do público para realização do processo falimentar. Caso haja insuficiência no patrimônio da estatal para efetuar obrigações, caberá ao ente federado (União, Estado, Distrito Federal ou Município) responder subsidiariamente (OLIVEIRA, 2017, p. 137).

Após entender o funcionamento e as normas que regem a empresa estatal, cabe agora compreender o seu surgimento no cenário brasileiro e importância para o desenvolvimento nacional.

\section{0 papel das empresas estatais no desenvolvimento nacional}

Atualmente, as empresas estatais estão presentes massivamente e em inúmeros setores no cumprimento de papéis estratégicos em seus respectivos Estados Nacionais. Em 2011, as empresas estatais representaram dez por cento do PIB mundial e tiveram uma venda conjunta de 3,6 trilhões de dólares (GROSSI; PAPENFUß; TREMBLAY, 2015, p. 274-275). Segundo a Forbes, em 2018, 60\% das dez maiores empresas eram estatais, pertencentes a China, Estados Unidos e Japão (OCTAVIANI; NOHARA, 2019, p. 21).

No caso do Brasil, historicamente, a presença do Estado na economia até o século XVIII era mínima em razão do desinteresse de Portugal pela colônia. Porém, a transferência do Estado português para o território colonial a fim de livrar-se de Napoleão trouxe consigo a tradição portuguesa de imbricação entre máquina política e econômica (OCTAVIANI; NOHARA, 2019, p. 45).

O início da participação do Estado na economia brasileira, segundo Giambiagi e Além (2008, p. 64), "não decorreu de uma atitude deliberada do Estado com vistas a ocupar o espaço do setor privado". Essa atuação estatal foi estimulada pelas seguintes razões:

a) a existência de um setor privado relativamente pequeno; b) os desafios colocados pela necessidade de enfrentar crises econômicas internacionais; c) o desejo de controlar a participação do capital estrangeiro, principalmente nos setores de utilidade pública e recursos naturais; d) o objetivo de promover a industrialização rápida de um país atrasado (GIAMBIAGI; ALÉM, 2008, p. 64). 
Dessa forma, o objetivo dessa atuação foi ocupar os espaços, até então, 'vazios', que correspondiam a atividades essenciais no desenvolvimento da economia e fortalecimento do próprio setor privado, principalmente em setores estratégicos (como a infraestrutura de estradas, energias e telecomunicações), consolidando o sistema capitalista. (GIAMBIAGI; ALÉM, 2008, p. 64).

Esse cenário de industrialização incipiente e o surgimento das empresas estatais está, em grande parte, relacionado a mudanças importantes no arranjo das atividades produtivas, no Brasil. Durante etapas de transição especialmente marcantes, tais entes estatais surgem como elementos para garantir a continuidade e ampliação da acumulação privada do capital (ABRANCHES, 1980, p. 8).

Assim, em 1808 foi fundada a primeira entidade estatal em território brasileiro, o Banco do Brasil (LEITE, 2007, p. 99). Tal circunstância abriu espaço para o início da formação do Brasil como nação independente em busca de instrumentos para soberania econômica (OCTAVIANI; NOHARA, 2019, p. 46).

A indústria da época estava ainda iniciante, somente após 1930 ganhando destaque e priorização do governo brasileiro. Tal preocupação veio com o estímulo do crescimento da atividade local, a fim de substituir as importações (GIAMBIAGI; ALÉM, 2008, p. 66).

O período de 1940 a 1950 caracterizou-se pela criação do Instituto de Resseguros do Brasil (1939), Companhia Siderúrgica Nacional (1942), Companhia Vale do Rio Doce (1942), a Fábrica Nacional de Motores (1943), a Companhia Hidrelétrica do São Francisco (1945), o Banco Nacional de Desenvolvimento Econômico (1952), a Petrobras (1953) e a Eletrobrás (1961) (GIAMBIAGI; ALÉM, 2008, p. 67-68).

No mundo, de 1960 a 1970, alcançou-se o ápice da participação do Estado na economia. E no Brasil não foi diferente. 0 auge desse momento foi o II Plano Nacional de Desenvolvimento, sob principal responsabilidade do sistema Eletrobrás, Petrobrás, Siderbrás e Telebrás, nas áreas habituais de infraestrutura (GIAMBIAGI; ALÉM, 2008, p. 70-71).

A expansão das empresas estatais e o investimento gerado por elas tiveram um papel muito importante para o desenvolvimento do Brasil. Segundo Giambiagi e Além (2008, p. 377), "foi um dos motores de crescimento da economia brasileira na segunda metade dos anos 1970, tendo tido ainda uma importância expressiva até o início dos anos 1980".

Depois de 1980, período conhecido como "década perdida"3, somado ao cenário econômico negativo das empresas estatais, tal fenômeno foi se reduzindo. Todavia, tais prejuízos refletidos pelas estatais não demonstravam ineficiência, mas sim op-

\footnotetext{
${ }^{3}$ Expressão conhecida no Brasil na década de 1980 devido à drástica redução do PIB e do processo hiperinflacionário, findados apenas após a adoção de planos estabilizadores (GIAMBIAGI; ALÉM, 2008, p. 83).
} 
ção política do Estado, uma vez que durante todo o procedimento de industrialização coube a tais entes a venda de produtos a preços subsidiados, com a finalidade de estímulo ao desenvolvimento do setor (GIAMBIAGI; ALÉM, 2008, p. 393-394).

Desse modo, a privatização (evento mundial na época, principalmente em países como Inglaterra e Chile) apresentou-se, também no Brasil, como uma saída para as dificuldades fiscais enfrentadas tanto pelas empresas estatais, quanto pelo país (GIAMBIAGI; ALÉM, 2008, p. 377).

Não obstante de o processo de privatização iniciar na década de 1980, apenas a partir de 1990 se torna uma prioridade econômica do governo brasileiro (GIAMBIAGI; ALÉM, 2008, p. 379). Tal processo deve ser observado como uma remodelação do papel do Estado, substituindo a produção pela regulação.

No caso do Brasil, a privatização justificou-se principalmente na "venda de ativos produtivos do setor público com o objetivo de geração de recursos para redução do estoque da dívida pública" (razão macroeconômica) (GIAMBIAGI; ALÉM, 2008, p. 379), além da promessa de maior eficiência do sistema privado (razão microeconômica) (GROSSI; PAPENFUß; TREMBLAY, 2015, p. 280).

0 processo de privatização brasileiro dividiu-se em três fases: uma durante a década 1980, outra entre 1990 e 1995, e por fim a que teve início em 1995 (GIAMBIAGI; ALÉM, 2008, p. 383).

A primeira fase (década de 1980) não se caracterizou por nenhuma grande empresa privatizada, mas se iniciou com o intuito de liquidar débitos do BNDES (que depois atuou como principal meio governamental para privatizações). Além disso, esse momento contribuiu para implantação de uma mentalidade pública a favor de tal procedimento (GIAMBIAGI; ALÉM, 2008, p. 383).

Já a segunda fase (em 1990) criou o Plano Nacional de Desestatização, um importante passo no processo privatizador brasileiro, visto que inserido numa estratégia do governo para reformas do mercado e caracterizado por ideias neoliberais. Essa etapa foi marcada pela venda de estatais clássicas, com enfoque de privatizar setores industriais (como siderurgia, petroquímica e fertilizante), alcançando, dentre outras, a Usiminas (GIAMBIAGI; ALÉM, 2008, 383-384).

Durante todo o processo privatizador, o Brasil adotou o sistema de vendas através de leilões públicos, que garantia maior rentabilidade, visto que possuía como finalidade a geração de receitas para abate na dívida pública (GIAMBIAGI; ALÉM, 2008, 384-385).

Já o início da terceira fase (em 1995) caracterizou-se, sobretudo, pela venda dos serviços públicos no setor de energia elétrica e telecomunicações. Em razão da receita e o porte das empresas envolvidas, tal período definiu-se pelas chamadas "megaprivatizações" (GIAMBIAGI; ALÉM, 2008, p. 385). 
O setor elétrico foi o primeiro, com a venda inicial de empresas federais pertencentes à holding Eletrobrás, como a Escelsa, Light, Furnas, Eletrosul, Eletronorte e Companhia Hidroelétrica do rio São Francisco (GIAMBIAGI; ALÉM, 2008, p. 392)

No setor de telecomunicações, iniciou-se a concessão dos serviços, qualificada como "venda do vento", visto que não foi feita a venda de ativos, mas sim o direito de concorrência. Depois, foram vendidas 25 empresas estaduais subsidiárias à holding Telebrás, conjuntamente com a Embratel (GIAMBIAGI; ALÉM, 2008, p. 393).

Segundo Giambiagi e Além (2008, p. 395-396), avaliando os resultados desse período privatizador, nota-se que, em geral, houve uma melhora no desempenho das empresas. Todavia, salientam que, além da privatização, outros fatores contribuíram para a evolução do setor (siderúrgico principalmente), como a liberalização dos preços e ajustes, feitos antes mesmo da venda destas. Dessa forma, não se pode afirmar que essas mudanças positivas nas empresas não teriam ocorrido se tais empresas não tivessem sido privatizadas (GIAMBIAGI; ALÉM, 2008, p. 395).

Como mencionado, a finalidade da venda das estatais até 1997 era o ajuste de déficits internos e externos, que deveriam ter ocorrido durante a fase de "bonança" proporcionada pela privatização (GIAMBIAGI; ALÉM, 2008, p. 400). Porém, tal cenário negativo que se esperava, chegou.

0 que ocorreu no segundo semestre de 1998 foi que, em face da moratória da dívida russa; do virtual desaparecimento do crédito internacional que ainda sobrevivera à crise das economias asiáticas de 1997; e das dificuldades domésticas para viabilizar os esforços de estabilização mediante a criação de uma "âncora fiscal”, o cenário negativo que se esperava - se o país não se ajustasse - para depois do ano 2000 foi antecipado em dois anos. De certo modo, o day after da privatização chegou no final de 1998, antes das privatizações terem acabado e provocando a necessidade de o país: a) implementar o ajuste fiscal tantas vezes protelado; b) recorrer novamente ao FMI e c) promover uma correção substancial da taxa de câmbio, para diminuir o déficit da conta-corrente (GIAMBIAGI; ALÉM, 2008, p. 400).

Mais recente, outro mecanismo com a finalidade de alienação das estatais foi o Programa de Parceria de Investimentos. Através da Lei no 13.334/16 (bem próxima à promulgação da lei no $13.303 / 16$ ), tinha a finalidade de, entre outros, celebrar contratos de parceria com a Administração nos casos de empreendimentos públicos (art. $1^{\circ}$ ), fortalecer o papel do Estado como regulador (art. $2^{\circ}$ ).

Após, seguiu-se o Decreto no 8.893/16 que buscava a venda de sociedades empresárias do setor de energia elétrica e o Decreto nำ 9.589/18 que determinou a inclusão das empresas estatais federais no PND para dissolvê-las. 
Apesar desse movimento pró-desestatização se repetir ao longo da história baseado em ideologias dos governantes, a doutrina entende que

A tarefa constitucionalmente determinada ao Estado brasileiro é (como se depreende dos comandos dos artigos 3o, 170 e 219 da Constituição de 1988, entra tantos outros) [...] a superação do subdesenvolvimento, da sua condição periférica, ou seja, uma tarefa mais ampla, complexa e transformadora do que as que são geralmente atribuídas ao Estado Social tradicional [...]. (BERCOVICI; OCTAVIANI, 2014, p. 80).

No mais, para Octaviani e Nohara (2019, p. 62), "As empresas estatais são instrumentos de tal projeto constitucional". Ainda, para Bandeira de Mello (2014, p. 198), tais entes são "fundamentalmente e acima de tudo, instrumentos de ação do Estado. 0 traço essencial caracterizador [...] é o de constituírem em auxiliares do Poder Público; logo, são entidades voltadas, por definição, à busca de interesses transcendentes aos meramente privados".

Todavia, o setor empresarial estatal ainda é extremamente relevante no contexto da economia nacional. 0 número de empresas estatais federais brasileiras e sua variedade na atuação (financeira ou produtiva) dão ao Estado brasileiro importância na fixação dos rumos da economia nacional (KLIASS, 2018, p. 24). Observe os gráficos a seguir. 0 gráfico 1 trata sobre a variação no número de empresas estatais federais no período de 2011 a 2018, enquanto o gráfico 2 demonstra o cenário do setor de atuação das estatais federais entre 2016 e 2019.

Gráfico 1 - Número de empresas estatais federais de 2011 a $2018^{4}$

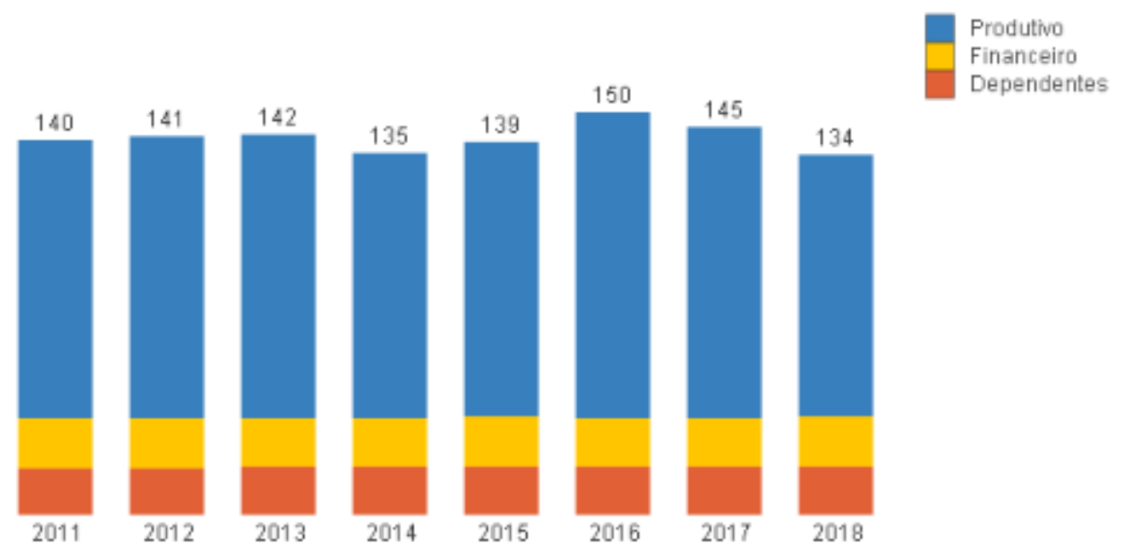

Fonte: BRASIL, 2020.

Gráfico 2 - Setores de atuação das empresas estatais federais brasileiras de 2016 a 2019

\footnotetext{
${ }^{4}$ Ainda, segundo dados do Ministério da Economia, o número de empresas estatais federais em 2020 é de 198, sendo 46 de controle direto e 152 indireto (subsidiárias) (BRASIL, 2020).
} 

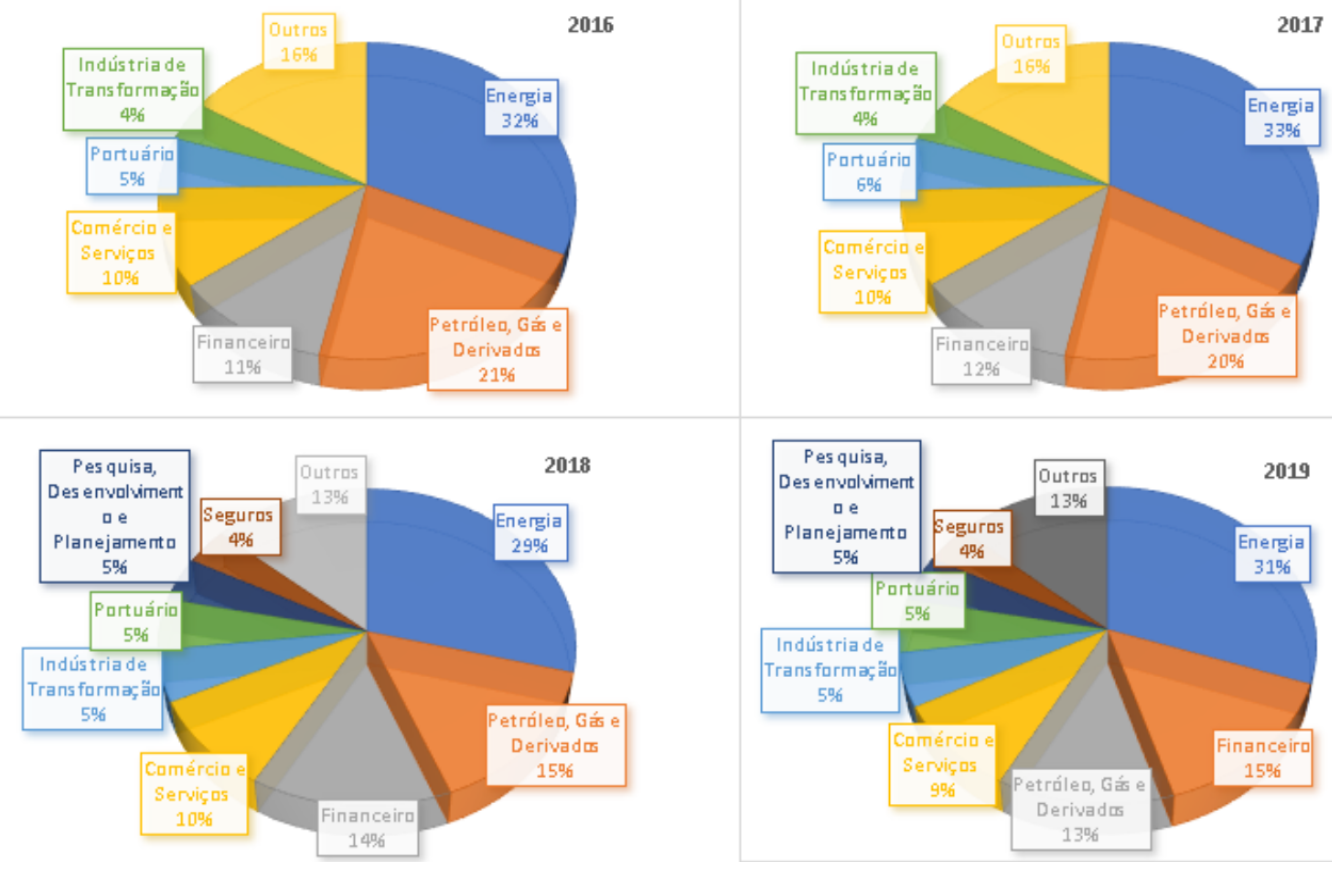

Fonte: elaborado pela autora no software Microsoft Excel.

Ao analisar os gráficos 1 e 2, nota-se um cenário com número expressivo de empresas estatais federais e amplitude do setor de atuação. Tais características podem possibilitar um "significativo papel na dinamização da economia de um país, frequentemente exercendo papel de indutoras de desenvolvimento, a depender do tipo de atividade e da forma como é desempenhada" (NOHARA, 2019, p. 676).

Nesse panorama, no qual as estatais jogam papel da mais extrema relevância, tome-se como exemplo a Petrobrás. Ao considerar apenas uma empresa estatal no ano de 2014, a Petrobrás alcançou o índice de 13\% de participação do PIB brasileiro (PETROBRAS, 2014, online). A estatal, em 2006, ainda realizou a maior descoberta mundial no segmento petroleiro dos últimos 50 anos, obtida com desenvolvimento tecnológico brasileiro, a Plataforma Continental brasileira do Pré-Sal (OCTAVIANI; NOHARA, 2019, p. 214).

Este resultado positivo obtido por tais entes foi refletido na Pesquisa de Inovação Tecnológica de $2008^{5}$ (baseado nos anos 2005-2008). Nessa pesquisa, o Instituto Brasileiro de Estatística e Geografia (IBGE) constatou que as empresas estatais federais apresentaram uma taxa de inovação tecnológica de 68,1\%. Enquanto isso, em outros tipos de empresas essa taxa foi de 38,6\% (PAULA, 2018, p. 117).

Dessa forma, em razão das empresas estatais não tomarem como prioritário somente metas de lucro, adquirem maior liberdade para efetuar "pesquisa básica, buscar tecnologias e implementar inovações mais amplas, arriscadas e de retorno de longo prazo, não necessariamente vinculadas aos seus negócios principais" (PAUlA, 2018, p. 118).

\footnotetext{
${ }^{5}$ Não foram encontrados dados posteriores ao ano de 2008.
} 


\section{Conclusão}

Resultantes da intervenção direta do Estado na ordem econômica, as empresas estatais - empresas públicas e sociedades de economia mista - contam com um regime jurídico próprio, disciplinado pela lei $n^{0}$ 13.303/2016, sobre o qual incidem tanto normas de direito público quanto de direito privado, caracterizando, segundo a doutrina, o denominado "regime híbrido".

Assim, tais entidades da Administração Pública indireta representam uma das principais formas de interação entre o Direito e a Economia no Brasil, razão pela qual o processo histórico de criação, consolidação e disciplina das estatais acompanha, de perto, as oscilações políticas que repercutem no complexo regramento da intervenção do Estado brasileiro na ordem econômica.

Nesse sentido, após décadas de significativo fortalecimento das empresas estatais, desde o final do século XX, o direito brasileiro vem experimentando uma redução de tais empresas no cenário econômico nacional, seja em razão das grandes privatizações, seja em consequência de normas que as aproximam, cada vez mais, das empresas privadas stricto sensu.

O histórico recente da Petrobrás, que em menos de uma década foi do auge ao declínio reflete muito da realidade das estatais no Brasil, desde sua disciplina jurídica até seu papel enquanto instrumento de intervenção do Estado na ordem econômica.

Assim, escândalos de corrupção enfrentados pela maior estatal nacional foram decisivos para a aprovação e entrada em vigor da nova lei das estatais (lei $\mathrm{n}^{\mathbf{o}}$ 13.303/2016), lei moderna e inovadora que, além de incorporar boas práticas comuns à esfera privada à gestão das estatais, estabelece instrumentos mais rígidos de controle e transparência, aptos a atrair investidores nacionais e estrangeiros e afastar práticas inapropriadas, mas recorrentes no histórico das estatais brasileiras.

Contudo, mais que meios para a obtenção de ganhos que representam o interesse público secundário, as empresas estatais devem ser compreendidas como instrumentos de intervenção do estado na ordem econômica, imprescindíveis à concretização de objetivos constitucionalmente assegurados, tais como a garantia da existência digna conforme ditames da justiça social, aptas a proporcionar meios para a retomada do desenvolvimento econômico e social no plano nacional.

\section{Referências bibliográficas}

ABRANCHES, Sérgio Henrique. A empresa pública no Brasil: uma abordagem multidisciplinar. Brasília: IPEA, 1980. 
BANDEIRA DE MELLO, Celso Antônio. Curso de direito administrativo. 31. ed. São Paulo: Malheiros, 2014.

BERCOVICI, Gilberto; OCTAVIANI, Alessandro. Direito e Subdesenvolvimento, in OCTAVIANI, Alessandro. Estudos, Pareceres e Votos de Direito Econômico. São Paulo: Singular, 2014, p. 80.

BRASIL. Constituição da República Federativa do Brasil de 1988. Brasília, DF. Disponível em: www.planalto.gov.br/ccivil_03/constituicao/constituicaocompilado.htm. Acesso em: 11 mar. 2020.

Lei $n^{\circ}$ 13.303, de 30 de junho de 2016. Dispõe sobre o estatuto jurídico da empresa pública, da sociedade de economia mista e de suas subsidiárias, no âmbito da União, dos Estados, do Distrito Federal e dos Municípios. Brasília, DF. Disponível em: http://www.planalto.gov.br/ccivil_03/_Ato20152018/2016/Lei/L13303.htm. Acesso em: 12 mar 2020.

Ministério da Economia. Secretaria de Coordenação e Governança das Empresas Estatais - SEST. Panorama das estatais. 2020. Disponível em: http://www.panoramadasestatais.planejamento.gov.br/QvAJAXZfc/opendoc.htm?document=paineldopanoramadasestatais.qvw\&lang=enUS\&host=QVS\%40srvbsaiasprd07\&anonymous=true/. Acesso em: 12 mar 2020.

Ministério do Planejamento, Desenvolvimento e Gestão. Secretaria de Coordenação e Governança das Empresas Estatais. Boletim das empresas estatais federais. 7. v. Brasília: MP, set. 2018. Disponível em: http://www.planejamento.gov.br/assuntos/empresas-estatais/publicacoes/7_boletim6.pdf/. Acesso em: 12 mar 2020.

. Supremo Tribunal Federal (Tribunal pleno). Ação direta de Inconstitucionalidade $n^{\circ}$ 1950/SP. Lei no 7.844, do Estado de São Paulo. Meia entrada assegurada aos estudantes regularmente matriculados em estabelecimento de ensino. Ingresso em casas de diversão, esporte, cultura e lazer. Competência concorrente entre União, Estados-membros e o Distrito Federal para legislar sobre Direito Econômico. Constitucionalidade. Livre iniciativa e ordem econômica. Mercado. Intervenção do Estado na economia. [...] Recorrente: Confederação Nacional do Comércio - CNC. Recorrido: Governador Do Estado De São Paulo Assembléia Legislativa Do Estado De São Paulo. Relator: Min. Eros Grau, 03 de novembro de 2005. Disponível em: http://redir.stf.jus.br/paginadorpub/paginador.jsp?docTP=AC\&docID=266808. Acesso em: 11 mar 2020.

Supremo Tribunal Federal (Tribunal pleno). Ação direta de Inconstitucionalidade $n^{\circ}$ 5624/DF. Medida cautelar em ação direta de inconstitucionalidade. Concessão parcial monocrática. Interpretação conforme à constituição. Art. 29, caput, da lei 13.303/2016. Venda de ações. Alienação do controle 
acionário de empresas públicas, sociedades de economia mista ou de suas subsidiárias e controladas. Necessidade de prévia autorização legislativa e de licitação. Voto médio. Medida cautelar parcialmente pelo plenário. I - A alienação do controle acionário de empresas públicas e sociedades de economia mista exige autorização legislativa e licitação pública. II - A transferência do controle de subsidiárias e controladas não exige a anuência do Poder Legislativo e poderá ser operacionalizada sem processo de licitação pública, desde que garantida a competitividade entre os potenciais interessados e observados os princípios da administração pública constantes do art. 37 da Constituição da República. III - Medida cautelar parcialmente referendada pelo Plenário do Supremo Tribunal Federal. [...] Recorrente: Federação Nacional Das Associações Do Pessoal Da Caixa Econômica Federal - FENAEE e Confederação Nacional Dos Trabalhadores Do Ramo Financeiro - CONTRAF/CUT. Recorrido: Presidente da República e Congresso Nacional. Relator: Min. Ricardo Lewandowski, 29 de novembro de 2019. Disponível em: http://portal.stf.jus.br/processos/downloadPeca.asp?id=15341840220\&ext=.pdf. Acesso em 12 mar 2020.

Supremo Tribunal Federal (Tribunal Pleno). Recurso Especial $n^{\underline{o}}$ 220.906/DF. Constitucional. Empresa Brasileira de Correios e Telégrafos. Impenhorabilidade de seus bens, rendas e serviços. Recepção do artigo 12 do Decreto-Lei no 509/69. Execução. Observância do regime de precatório. Aplicação do artigo 100 da Constituição Federal. Recorrente: Empresa Brasileira de Correios e Telégrafos - ECT. Recorrido: Ismar José da Costa. Relator: Min. Maurício Corrêa, 14 de novembro de 2002. Disponível em: http://redir.stf.jus.br/paginadorpub/paginador.jsp?docTP=AC\&docID=249355. Acesso em: 12 mar 2020.

. Superior Tribunal Federal. Súmula $n^{\circ}$ 517. As sociedades de economia mista só têm foro na Justiça Federal, quando a União intervém como assistente ou opoente. Brasília, DF: Superior Tribunal Federal, 1969. Disponível em: http://www.stf.jus.br/portal/jurisprudencia/listarJurisprudencia.asp?s1=517.NUME.\%20NA0\%20S.FLSV.\&base=baseSumulas. Acesso em: 11 mar 2020.

. Superior Tribunal Federal. Súmula no 556. É competente a Justiça Comum para julgar as causas em que é parte sociedade de economia mista. Brasília, DF: Superior Tribunal Federal, 1977. Disponível em: http://www.stf.jus.br/portal/jurisprudencia/menuSumarioSumulas.asp?sumula=2793. Acesso em: 11 mar 2020.

CARVALHO FILHO, José dos Santos. Manual de Direito Administrativo. 34. ed. São Paulo: Atlas, 2020.

DI PIETRO, Maria Sylvia Zanella. Direito Administrativo. 33. ed. Rio de Janeiro: Forense, 2020. 
FIGUEIREDO, Leonardo Vizeu. Lições de Direito Econômico. 7 ed. Rio de Janeiro: Forense, 2014.

FONTOURA, Pedro Burman da. O necessário aprimoramento dos mecanismos de controle para a intervenção estatal na economia. Revista Digital de Direito Administrativo, v. 6, n. 2, p. 114-134, 2019.

GIAMBIAGI, Fabio; ALÉM, Ana Cláudia Duarte de. Finanças públicas: teoria e prática no Brasil. 3. ed. Rio de Janeiro: Elsevier, 2008.

GROSSI, Giuseppe; PAPENFUß, Ulf; TREMBLAY, Marie-Soleil. Corporate governance and accountability of State-Owned enterprises: relevance for science and society and interdisciplinary research perspectives. International Journal of Public Sector Management, v. 28, n. 4/5, p. 274-285, 2015.

KLIASS, Paulo. A configuração das empresas estatais federais: evolução de 2003 a 2017. Boletim de Análise Político-Institucional, n. 15, p. 13-25, jul./dez. 2018.

LAKATOS, Eva Maria; MARCONI, Marina de Andrade. Fundamentos da metodologia científica. 5. ed. São Paulo: Atlas, 2003.

LEITE, Sando Grangeiro. A evolução das empresas públicas e sociedades de economia mista no contexto jurídico brasileiro. Revista do TCU, n. 109, p. 99-110, mai./ago. 2007.

MALUF, Sahid. Teoria Geral do Estado. 34. ed. São Paulo: Saraiva Educação, 2018.

NOHARA, Irene Patrícia. Direito Administrativo. 9. ed. São Paulo: Atlas, 2019.

OCTAVIANI, Alessandro; NOHARA, Irene Patrícia. Estatais. São Paulo: Thomson Reuters Brasil, 2019.

OLIVEIRA, Rafael Carvalho Rezende. Curso de Direito Administrativo. 5. ed. Rio de Janeiro: Forense, 2017.

PAULA, Fábio de Oliveira. Inovação nas Empresas Estatais Federais Brasileiras: fatores influentes e agenda para pesquisas futuras. Boletim de Análise Político-Institucional, n. 15, p. 115-121, jul./dez. 2018.

PETROBRÁS. Participação do setor de petróleo e gás chega a 13\% do PIB brasileiro. Rio de Janeiro: Agência Petrobrás, jun. 2014. Disponível em: https://www.agenciapetrobras.com.br/Materia/ExibirMateria?p_materia=976480. Acesso em: 13 mar 2020. 